\author{
Military Technical College \\ Kobry El-Kobbah, \\ Cairo, Egypt
}

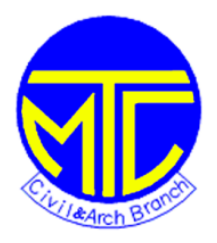

\title{
Finite element modeling of pre-stressed hollow core slabs
}

\author{
Ali N. Deeb* \\ M. Abou Zeid Tarkhan** \\ E. M. El-Tehewy***
}

\begin{abstract}
$\underline{\text { Abstract: }}$
In this research, an analytical model is presented to study the shear behavior of prestressed hollow core slabs. The study is conducted with respect to the shear considering a concentrated line load (in absence of concrete topping and filling of cores) using finite elements method adopted by the computer program ANSYS. The finite element models are developed using a smeared cracking approach for the concrete and three-dimensional link elements for the prestressing strands. The ANSYS finite element analysis results are compared with the experimental data of two prestressed hollow core slabs. The comparisons are made for load-deflection curves, failure load and crack pattern. The accuracy of the finite element models is assessed by comparison with the experimental results, which are to be in good agreement.
\end{abstract}

\section{Keywords:}

Prestressed hollow core slabs, Shear failure, Finite-element analysis, Pre-stressing strands

\section{Introduction:}

Hollow-core units were developed in the 1950s, when long-line prestressing techniques evolved. For more than 30 years, the type of units produced changed little. Extensive research performed in Europe in the 1980s, led to technology advances allowing the economical production of units.

Precast, prestressed hollow core slabs (PHC slabs) are among the most common load bearing concrete elements in the world. They are widely used in floors and roofs of office, residential, commercial and industrial buildings.

The PCI Manual for the Design of Hollow Core Slabs [1] notes that there are essentially two methods used to produce hollow-core units in the United States. One is a dry-cast (or extrusion) system in which a very low-slump concrete is forced through the casting machine. Cores in the units are formed with augers or tubes, and the concrete is compacted around the cores. The second system uses a higher slump concrete. The sides are created by stationary forms (or by slip forming) with forms attached to the machine. Cores are typically created by pneumatic tubes attached to the

\footnotetext{
* Ph.D. Student, Civil Engineering Department, Syrian Armed Forces

** ASS Prof. Dr., Helwan University, Cairo, Egypt

*** ASS Prof. Dr., Lecturer, Military Technical College, Cairo, Egypt
} 
form or by slip forming with long tubes attached to the casting machine.

In order to verify the as-cast shear capacity of prestressed hollow-core slabs, a suitable test setup must be designed to take into account all variables, which may contribute either negatively or positively to the shear capacity of the slabs.

The selection of the type of load used for a shear test (uniform or concentrated) can also have an effect on the member behavior. A common approach for shear testing is to use a concentrated load, resulting in shear forces that are essentially constant between the load and the support reaction.

Two full-scale tests on one-way floor systems $3.5 \times 1.2 \times 0.15 \mathrm{~m}$ height are performed in order to investigate the shear capacity behavior of prestressed hollow core slabs and to check the results of ANSYS program output. A 3D-nonlinear finite element model is developed and the analytical results are verified by comparison with the experimental test results.

The finite element method is now well accepted as the most powerful general technique for the numerical solution of a variety of engineering problems and applied to analyze the stresses of solids. In the realm of linear analysis, the finite element method is now widely used as a design tool. A similar acceptance in nonlinear analysis problems depends on two major factors. First, the increase in computational effort, which is required for nonlinear problems necessitate that considerable computing power, be available at low cost to the designer. The second major factor is related to the level of complexity of nonlinear analysis. Before application of nonlinear methods can become commonplace in design situations, the accuracy and reliability of the proposed models, have to be established beyond doubt. The development of improved element characteristics and more efficient nonlinear solution algorithms as well as the experience gained in their application to engineering problems has ensured that nonlinear finite element analysis can now be performed with some confidence.

Thus, barriers to the wide use of nonlinear finite element techniques are gradually removed. Nevertheless, difficulties still abound whose solution will require much effort on the part of researchers and designers.

The behavior of reinforced concrete structures is distinctly nonlinear, because of several factors: (1) nonlinear material behavior of concrete and steel and their interaction through bond and dowel action; (2) cracking of concrete; and (3) time dependent effects such as creep, shrinkage, temperature, and load history. In dealing with these problems in an analytical setting, several nonlinear solution algorithms are now available.

A large number of available software like sap2000, LUSAS, and ANSYS etc incorporate finite elements based analysis. In this paper an attempt has been made with ANSYS (version 11) [2] software to bring into focus the versatility and powerful analytical capabilities of finite elements technique by objectively modeling the complete response of the PHC slabs tested. The finite elements model uses a smeared cracking approach to model the reinforced concrete and link spar 8 elements to model the strand composites. The prestressing force is applied as joint loads. This model provides a valuable supplement to the laboratory investigations.

\section{Test programme:}

The object of the experimental work is to check the results obtained from the ANSYS program. Therefore, two hollow core slabs, which were prefabricated, are tested under concentrated load. The slabs have the same cross-section and prestressing strand. They are of $3.5 \mathrm{~m}$ length, $1.2 \mathrm{~m}$ width and $0.15 \mathrm{~m}$ height. Each slab has twelve elliptical-shaped openings, and one oblong-shaped in the mid of slabs width. It is reinforced by eight pre-stressing seven-wire strands by along its bottom surface, (Fig.1). Table 1 and 2 summarizes the slab properties and strands respectively. 


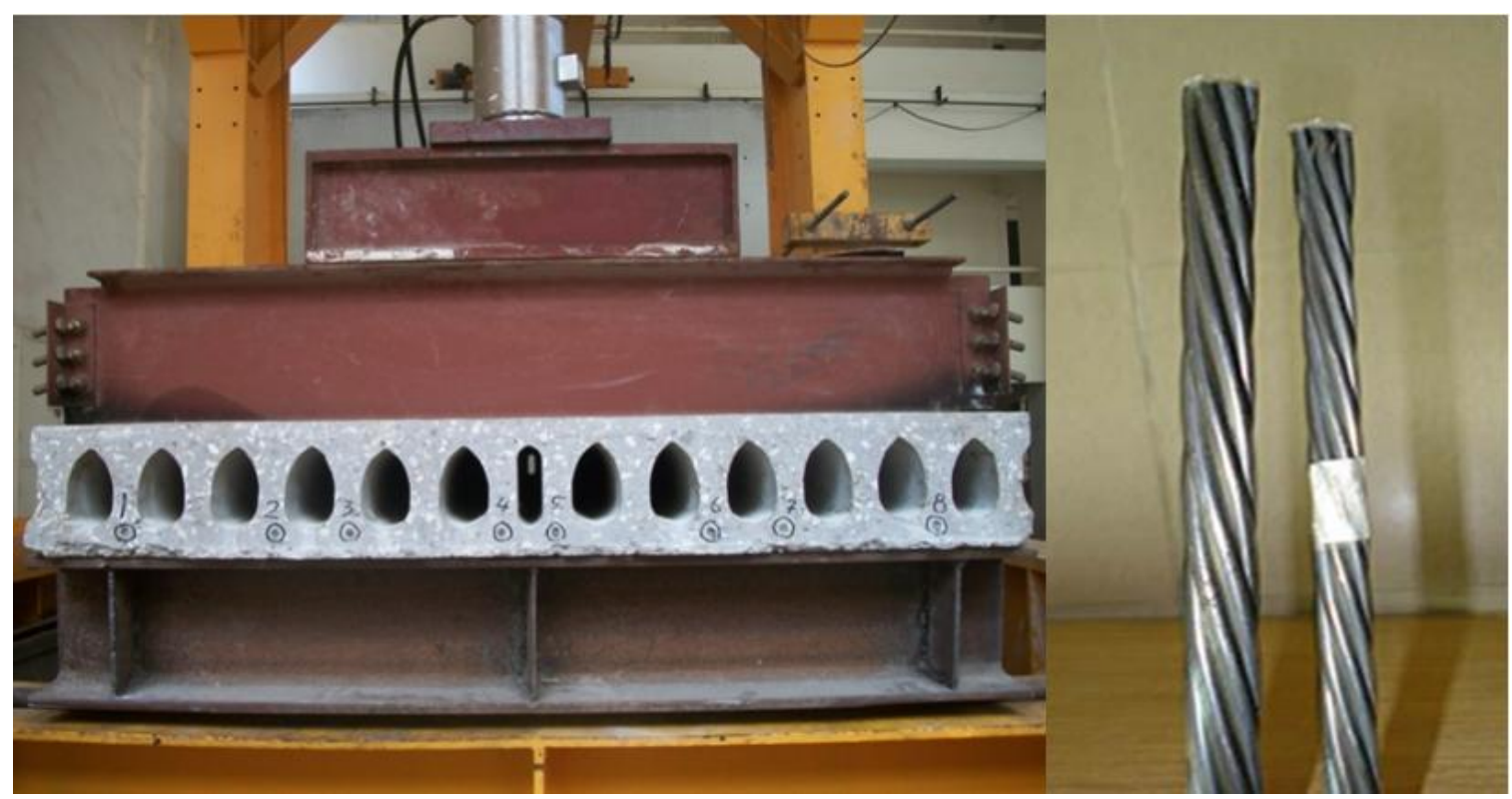

Figure (1): Nominal cross-sections for test slabs and seven-wire prestressing strands Table (1): Summary of slab properties

\begin{tabular}{|c|c|c|c|c|c|c|}
\hline Slabs & $\begin{array}{c}\text { Slab } \\
\text { Length } \\
(\mathrm{mm})\end{array}$ & $\begin{array}{c}\text { Nominal } \\
\text { Slab Depth } \\
(\mathrm{mm})\end{array}$ & $\begin{array}{c}\text { Slab Section } \\
\text { Area } \\
\left(\mathrm{Cm}^{2}\right)\end{array}$ & $\begin{array}{c}\text { Compressive } \\
\text { Strength }\left(f_{c}^{\prime}\right) \\
\left(\mathrm{N} / \mathrm{mm}^{2}\right)\end{array}$ & $\begin{array}{c}\text { Distance } \\
(\mathrm{a}) \\
(\mathrm{mm})\end{array}$ & $\begin{array}{c}\text { Prestressing } \\
\text { Force } \\
(\mathrm{KN})\end{array}$ \\
\hline SA & 3500 & 150 & 1234.4 & 43.57 & 300 & 518 \\
\hline SB & 3500 & 150 & 1234.4 & 43.57 & 450 & 518 \\
\hline
\end{tabular}

Table (2): Summary of pre-stressing seven-wire strands

\begin{tabular}{|l|c|c|c|c|c|c|c|}
\hline Strands & $\begin{array}{c}\text { Cross } \\
\text { section } \\
\left(\mathrm{mm}^{2}\right)\end{array}$ & $\begin{array}{c}\text { Nom. } \\
\text { Diameter } \\
(\mathrm{mm})\end{array}$ & $\begin{array}{c}\text { Mass } \\
(\mathrm{g} / \mathrm{m})\end{array}$ & $\begin{array}{c}\text { Breaking } \\
\text { load } \\
(\mathrm{KN})\end{array}$ & $\begin{array}{c}\text { Ultimate } \\
\text { strength } \\
\left(\mathrm{KN} / \mathrm{mm}^{2}\right)\end{array}$ & $\begin{array}{c}\text { Yield } \\
\text { strength } \\
\left(\mathrm{KN} / \mathrm{mm}^{2}\right)\end{array}$ & $\begin{array}{c}\text { Modulus } \\
\text { elasticity } \\
\left(\mathrm{KN} / \mathrm{mm}^{2}\right)\end{array}$ \\
\hline 7-wire & 54.84 & 9.53 & 432 & 102.3 & 1.860 & 1.679 & 197.5 \\
\hline
\end{tabular}

The slabs were supported on the flanges of two I-beams and loaded with a concentrated load P, (Fig.2). The load acts on an I-beam with a length equal to the width of test slab at the distance (a) of $2 \mathrm{~h}(300 \mathrm{~mm})$ for slab SA and $3 \mathrm{~h}(450 \mathrm{~mm})$ for slab SB, (Fig.3). Were (a) the distance from the centre line of the applied load to the middle of the bearing surface, and (h) is the slab thickness. The load was applied in increments of $10 \mathrm{KN}$. 


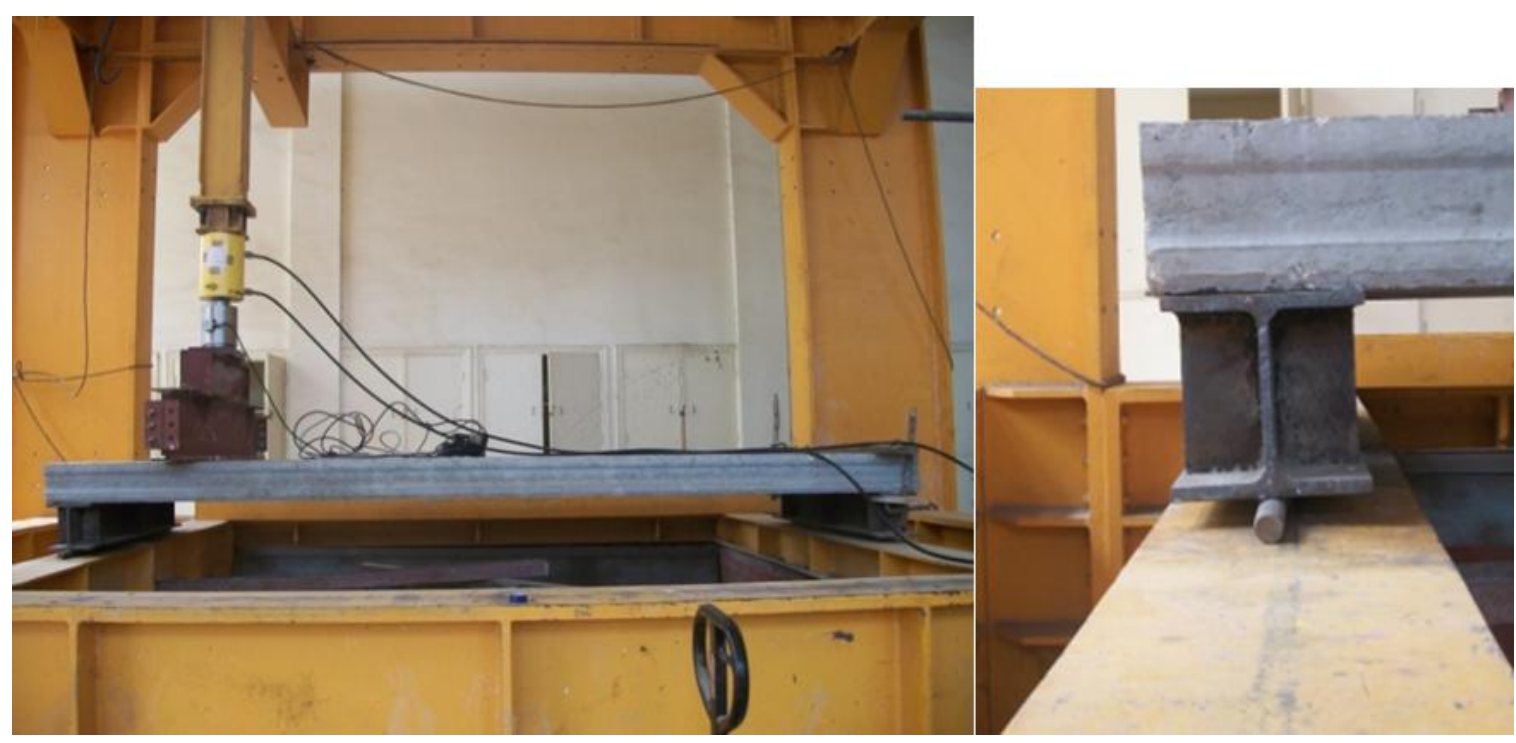

Figure (2): Tested slabs
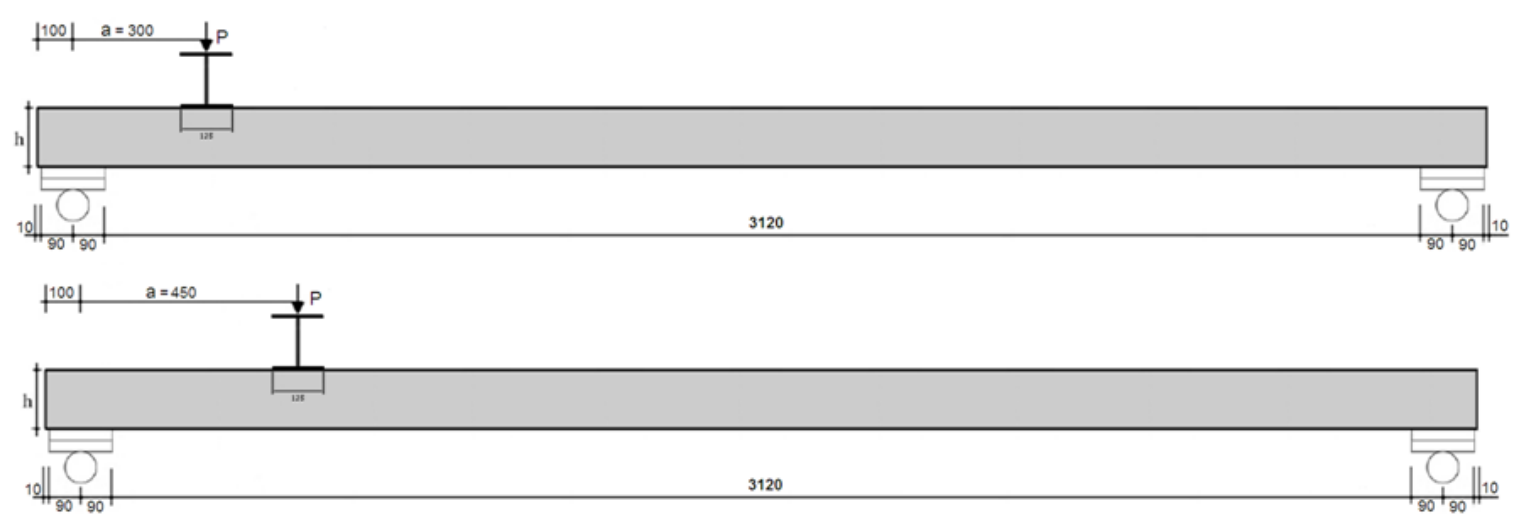

Figure (3): Loading of slabs $S A$ and $S B$

\section{Finite element modeling:}

The finite elements analysis included modeling of the prestressed hollow core slabs tested.

\subsection{Concrete:}

A solid element is used to model the concrete. To be able to account for the failure modes of concrete cracking in tension and crushing in compression, a special brittle finite element material model has to be used. In this study, the element (Solid 65) was used to model the concrete. The element (Solid65) has eight nodes with three degrees of freedom at each node (translations in the nodal $\mathrm{x}, \mathrm{y}$, and $\mathrm{z}$ directions). This element is capable of plastic deformation, cracking in three orthogonal directions, and crushing. A $2 \times 2 \times 2$ lattice of integration points is used with Gaussian integration procedure. This means that for each element there are eight integration points. The geometry, node locations, and the coordinate system for this element are shown in Figure 4, [2]. 


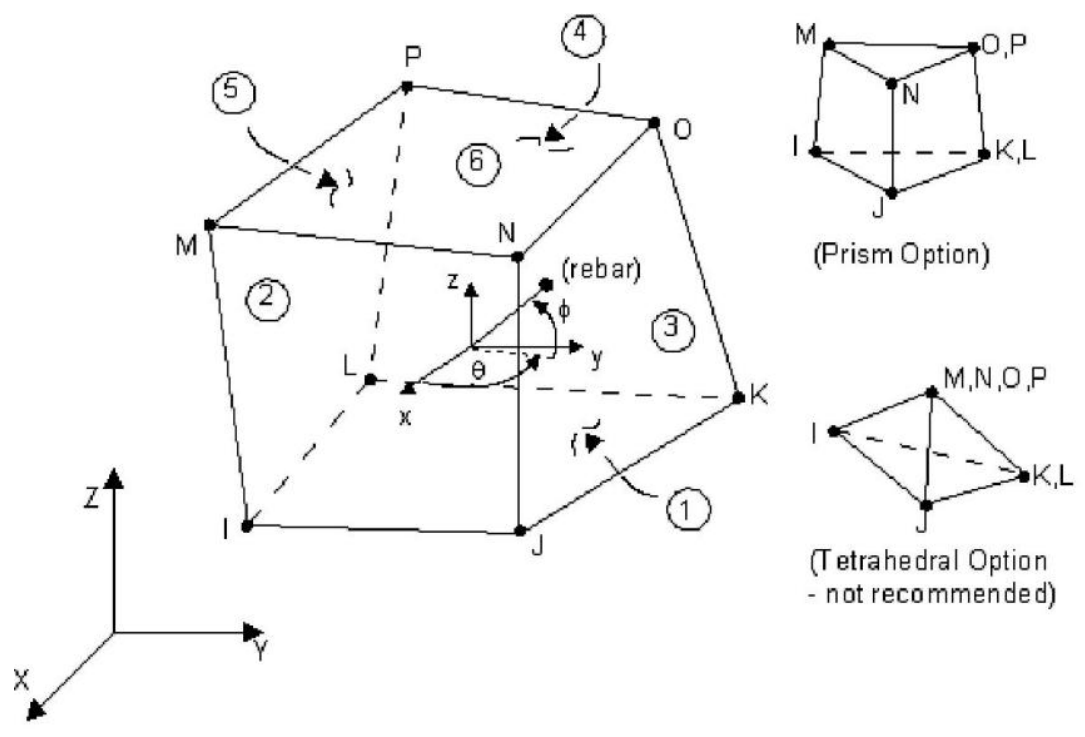

Figure (4): (Solid 65) 3-D concrete element

The element material is assumed to be isotropic and the most important aspect of this element is the treatment of nonlinear material properties where concrete is capable of directional cracking and crushing besides incorporating plastic and creep behavior.

The additional concrete material data needed for (Solid 65) are shear transfer coefficients, tensile stresses and compressive stresses. Typical shear transfer coefficients range from zero for a smooth or open crack to one for rough or closed crack. For concrete, (ANSYS) requires input data for material properties as follows:

- The corresponding elastic modulus $\left(E_{c}\right)$, (calculated as $\left.E_{C}=4400 \sqrt{f_{c}^{\prime}}\right)$

- Ultimate uniaxial compressive strength $\left(f_{c}^{\prime}\right)$

- Ultimate uniaxial tensile strength $\left(f_{c t r}\right)$, (calculated as $\left.f_{c t r}=0.6 \sqrt{f_{c}^{\prime}}\right)$

- Poisson's ratio $(v)=0.2$

- Shear transfer coefficient $\left(\beta_{t}\right)$. The shear transfer coefficient used in this study was taken equal to 0.2 for open cracks and 0.9 for closed cracks.

- Compressive uniaxial stress-strain relationship for concrete.

The concrete is assumed homogeneous and initially isotropic [2]. The compressive uniaxial stress-strain relationship for concrete model is obtained by using the following equations to compute the multi-linear isotropic stress-strain curve for the concrete as demonstrated [3] and shown in Figure 5.

$$
\begin{array}{llrl}
f_{c} & =\varepsilon E & \text { For } & 0 \leq \varepsilon \leq \varepsilon_{1} \\
f_{c}=\frac{\varepsilon E}{1+\left(\frac{\varepsilon}{\varepsilon_{0}}\right)^{2}} & \text { For } & \varepsilon_{1} \leq \varepsilon \leq \varepsilon_{0} \\
f_{c}=f_{c}^{\prime} & \text { For } & \varepsilon_{0} \leq \varepsilon \leq \varepsilon_{u} \\
\varepsilon_{0}=\frac{2 f_{c}^{\prime}}{E} & , & \varepsilon_{1} \text { at } 0.3 f_{c}^{\prime}
\end{array}
$$

Where:

$f_{c}:$ Stress at any strain $\varepsilon .\left(N / \mathrm{mm}^{2}\right)$.

$f_{c}^{\prime}$ : Characteristic compressive strength for concrete at 28 days. $\left(\mathrm{N} / \mathrm{mm}^{2}\right)$. 
$\varepsilon_{0}$ : Strain at the ultimate compressive strength. $\left(f_{c}^{\prime}\right)$.

The solution output associated with element (Solid 65) are the nodal displacements included in the overall nodal solution and other additional element output such as concrete nonlinear integration point solution since cracking or crushing may occur at any integration point. In addition, the cracking or crushing status for each integration point can be reviewed in all directions where the cracking plane is defined by two cracking angles $\left(\theta_{\mathrm{cr}} \& \phi_{\mathrm{cr}}\right)$ as shown in Figure 6, [2].

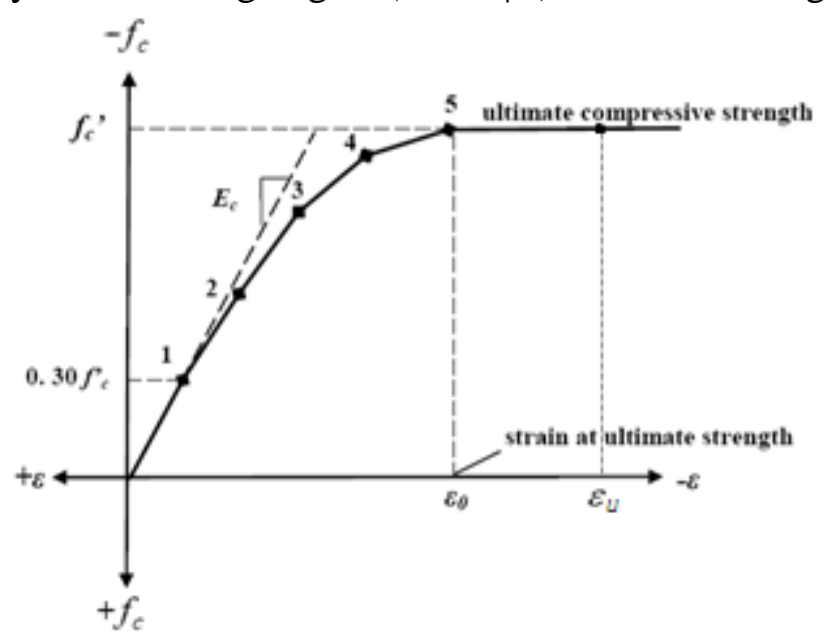

Figure (5): Simplified compressive uniaxial stress- strain curve of concrete

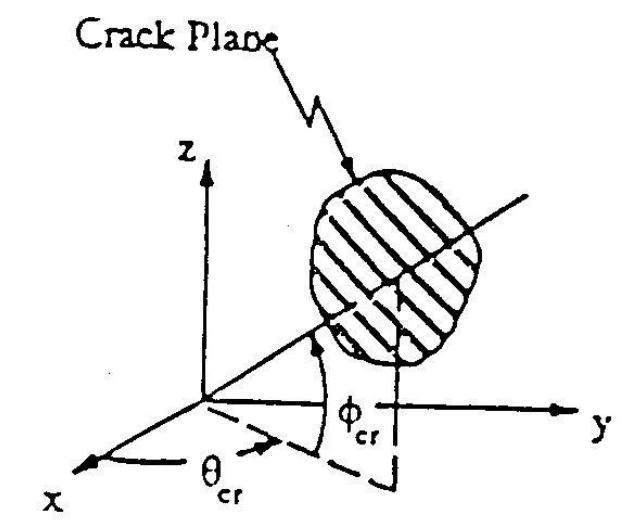

Figure (6): Cracking plane in (Solid 65)

\subsection{Pre-stressing strands:}

To model prestressing strands the 3-D spar element (Link 8) available in the elements library of the (ANSYS) program was used. (Link 8) is a 2-nodded element, which may be used in a variety of engineering applications. The element may be thought of as a truss, tendon, link, or a spring element depending on the application. The three-dimensional spar element (Link 8) is a uniaxial tension-compression element with three degrees of freedom at each node: translation in the nodal $\mathrm{x}$, $\mathrm{y}$, and $\mathrm{z}$ directions. The element is also capable of plastic deformation, creep, swelling, stress stiffening, and large deflection capabilities are included [2]. A perfect bond between the concrete and pre-stressing strands is considered. In the present study, the prestressing strand was connected between nodes of each adjacent concrete solid element, so the two materials shared the same nodes. Element (Link 8) is defined by two nodes, the cross-sectional area, an initial strain, and the material properties. The pre-stressing strands of area $54.84 \mathrm{~mm}^{2}$ are used. The yield strength, ultimate strength, and modulus of elasticity were 1679, 1860, and $197500 \mathrm{~N} / \mathrm{mm}^{2}$ respectively. A Poisson's 
ratio of 0.3 is used for the pre-stressing strand. The geometry, node locations, and the coordinate system for this element are shown in Figure 7.

The prestressing force is applied as nodal forces distributed uniformly along the development length $l_{d}$ of the prestressing strands. The development length turned out to be about $1.75 \mathrm{~m}$ (i.e. half-length of the test slab).

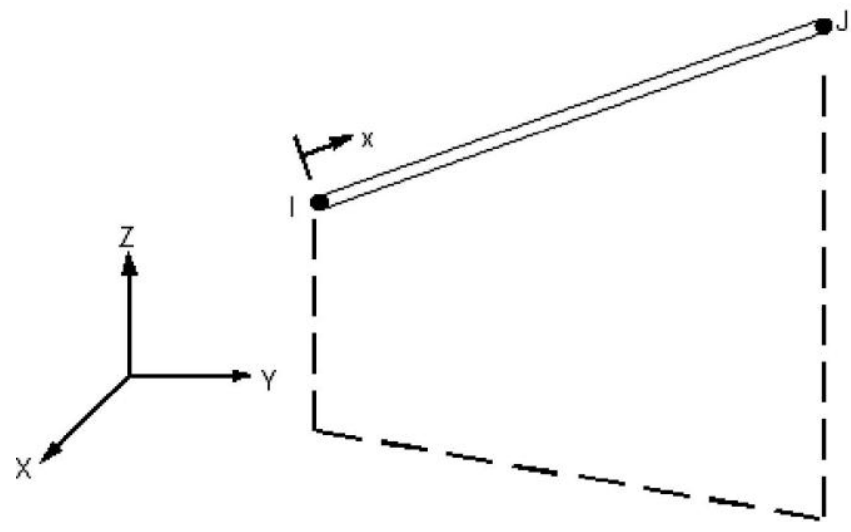

Figure (7): Geometry, node location, and coordinate system of 3-D spar element (Link 8)

\subsection{Finite element model:}

The numerical model developed for pre-stressed hollow core slabs, and the typical dimensions of the finite element model are show in Figure 8.

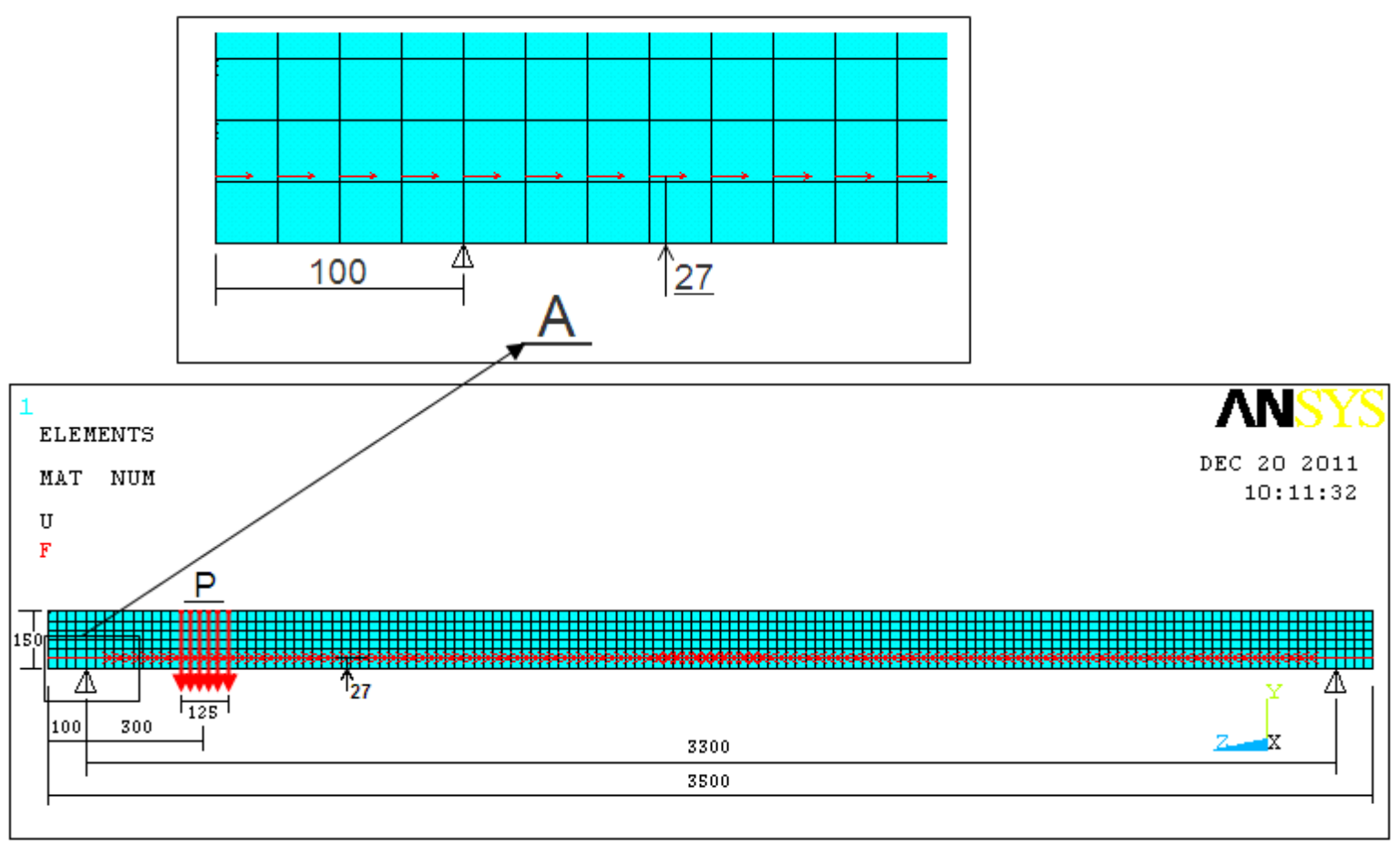

Figure (8): Finite element model for pre-stressed hollow core slab (Show applied prestressing load) 
The mesh layout, which used in the present model, was the same in all analytical models. Using a single layer of integrated elements to represent the depth of the slab is obviously incorrect; therefore, six elements were used to represent the depth of the slab. The geometry of the mesh layout is shown in Figure 9.

The load was applied on the nodes of the upper surface of slabs in increments of $10 \mathrm{KN}$ as in the experimental test. In the linear range, this load increment was divided into 2 sup-steps. Close to the failure load, increment was divided into 10 sup-steps.
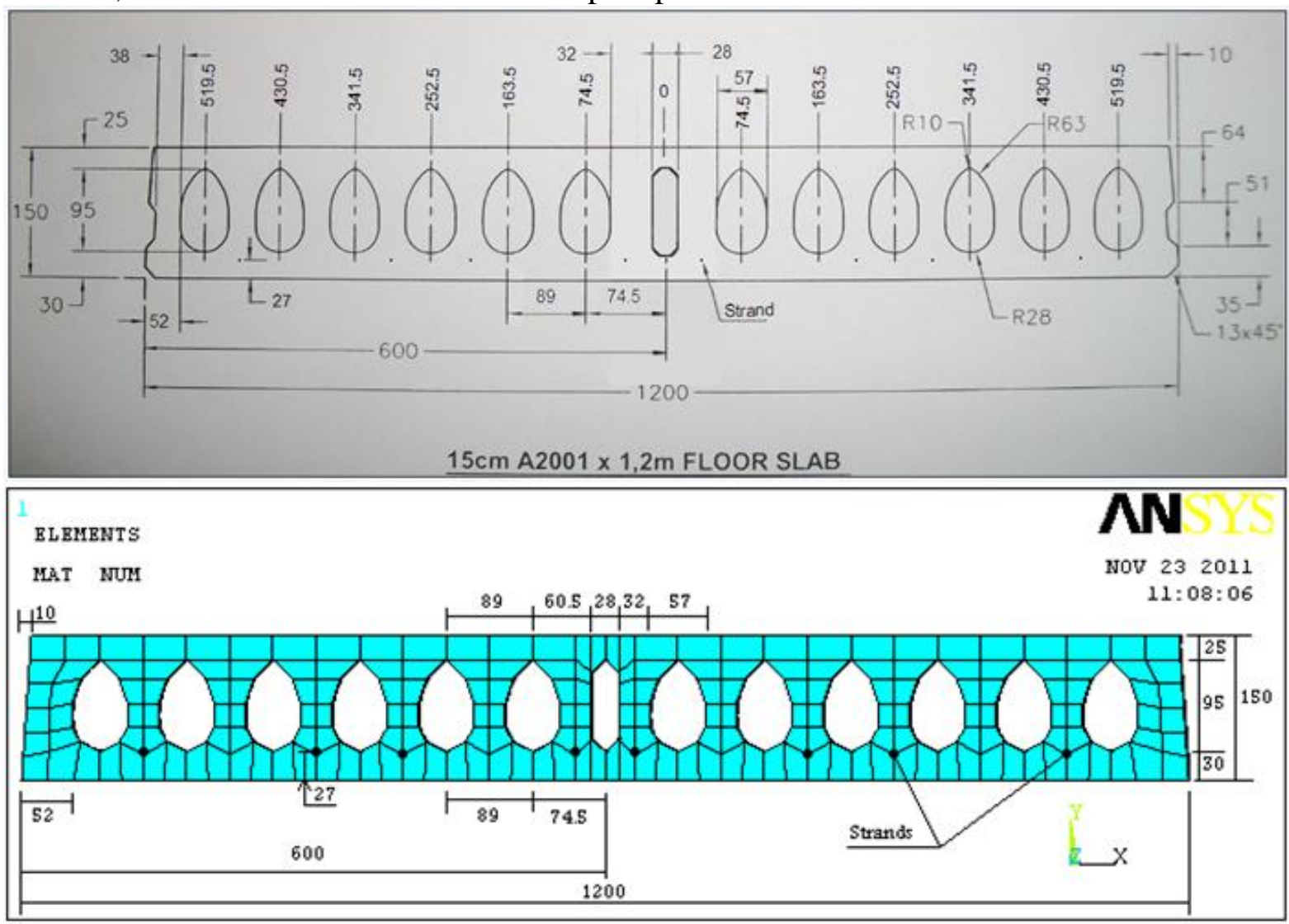

Figure (9): Typical dimensions of the cross-sectional area and strands

\section{Discussion of Results:}

\subsection{Load deflection curves:}

The deflections of the slabs at each vertical load increment were taken from output results to construct the load-deflection curves and the crack propagation was observed for each model. The failure point is determined in the analytical model at the load value where the computer program indicates suddenly large deflection.

For all models, the load-deflection curves of concrete were recorded at middle width of slabs on the bottom surface at two locations: first directly under vertical load, second at point A (were the maximum deflection occurred) as shown in Fig.10. 


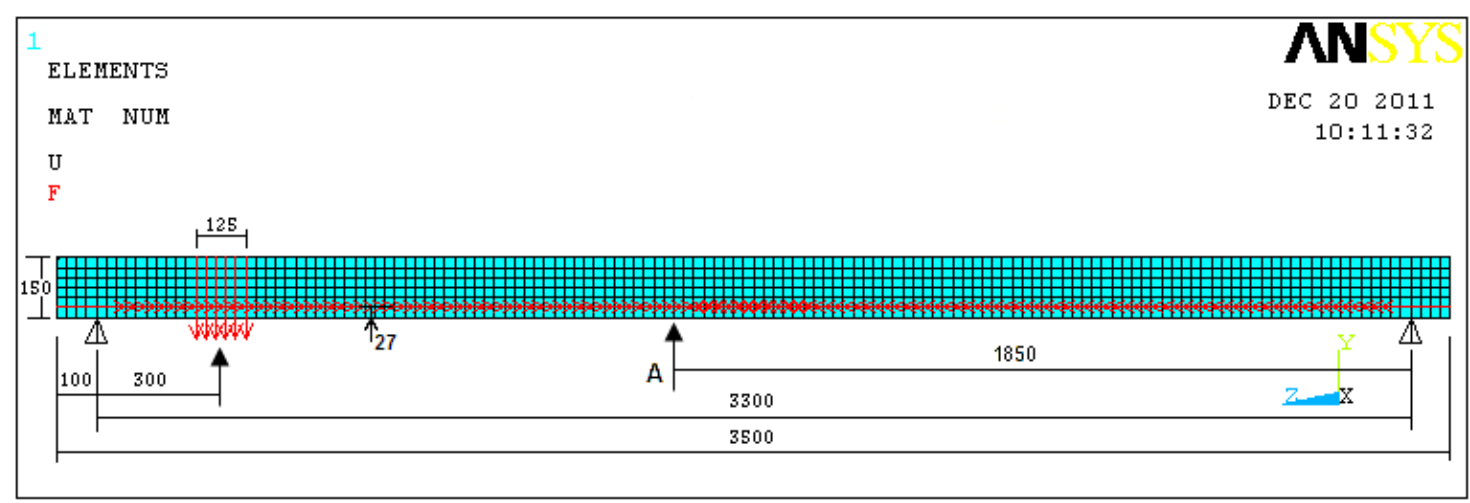

Figure (10): Points were recorded deflection (Under vertical load and at point A)

The experimental and numerical load-deflection curves obtained for the prestressed hollow core slabs are illustrated in Figures 11 and 12. It is clear that the failure mode of the analytical model is similar to that in the experimental model, and behaves in the same manner. The curves show good agreement between the finite element analysis and the experimental results throughout the entire range of behavior and failure mode. However, for the two prestressed hollow core slabs tested, the finite element model is stiffer than the actual slabs. Several factors may cause the higher stiffness in the finite element models. The bond between the concrete and prestressing strand is assumed to be perfect (no slip) in the finite element analyses, but for the actual slabs the assumption would not be true, since slip occurs. Therefore, the composite action between the concrete and prestressing strand is lost in the actual hollow core slabs. In addition, the micro-cracks produced by drying shrinkage and handling are present in the concrete to some degree. These would reduce the stiffness of the actual prestressed hollow core slabs, while the finite element models do not include micro-cracks due to factors that are not incorporated into the models.

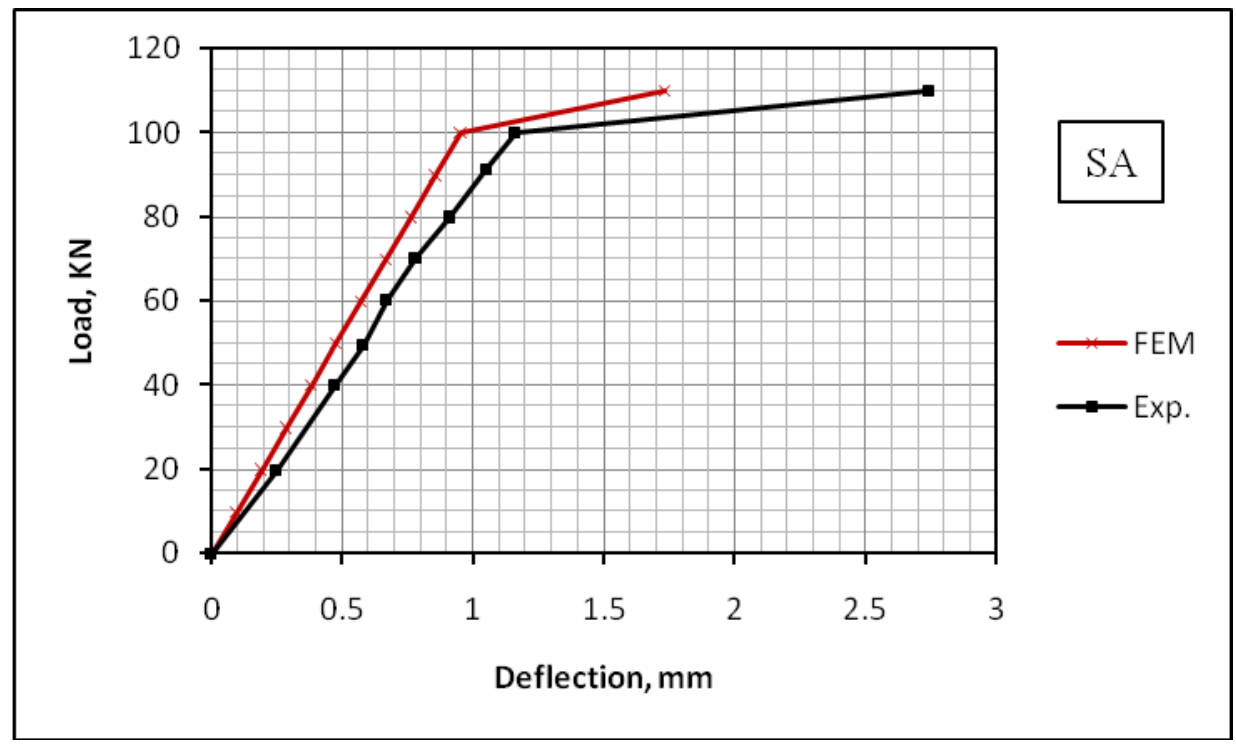


Proceedings of the $\mathbf{9}^{\text {th }}$ ICCAE-9 Conference, 29-31 May, 2012

\begin{tabular}{|l|l|}
\hline CS & 4 \\
\hline
\end{tabular}

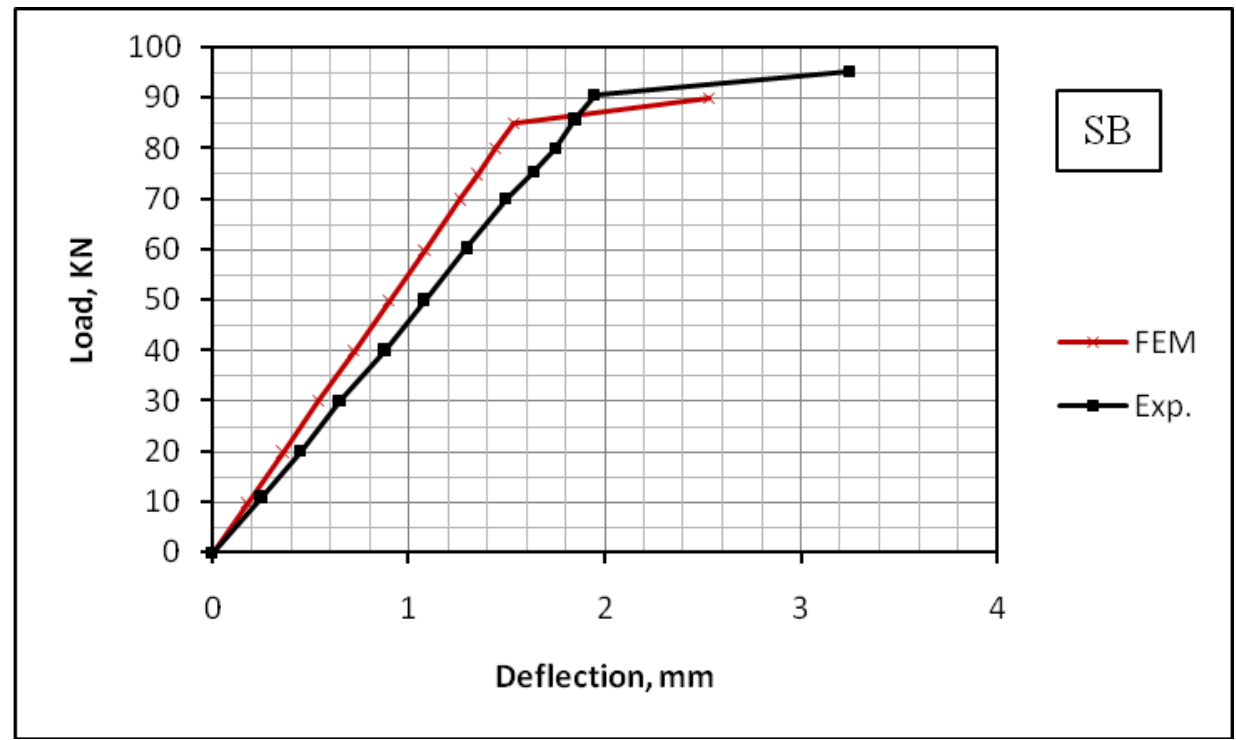

Figure (11): Load-deflection curves for slabs $S A$ and $S B$ (At point under vertical load)

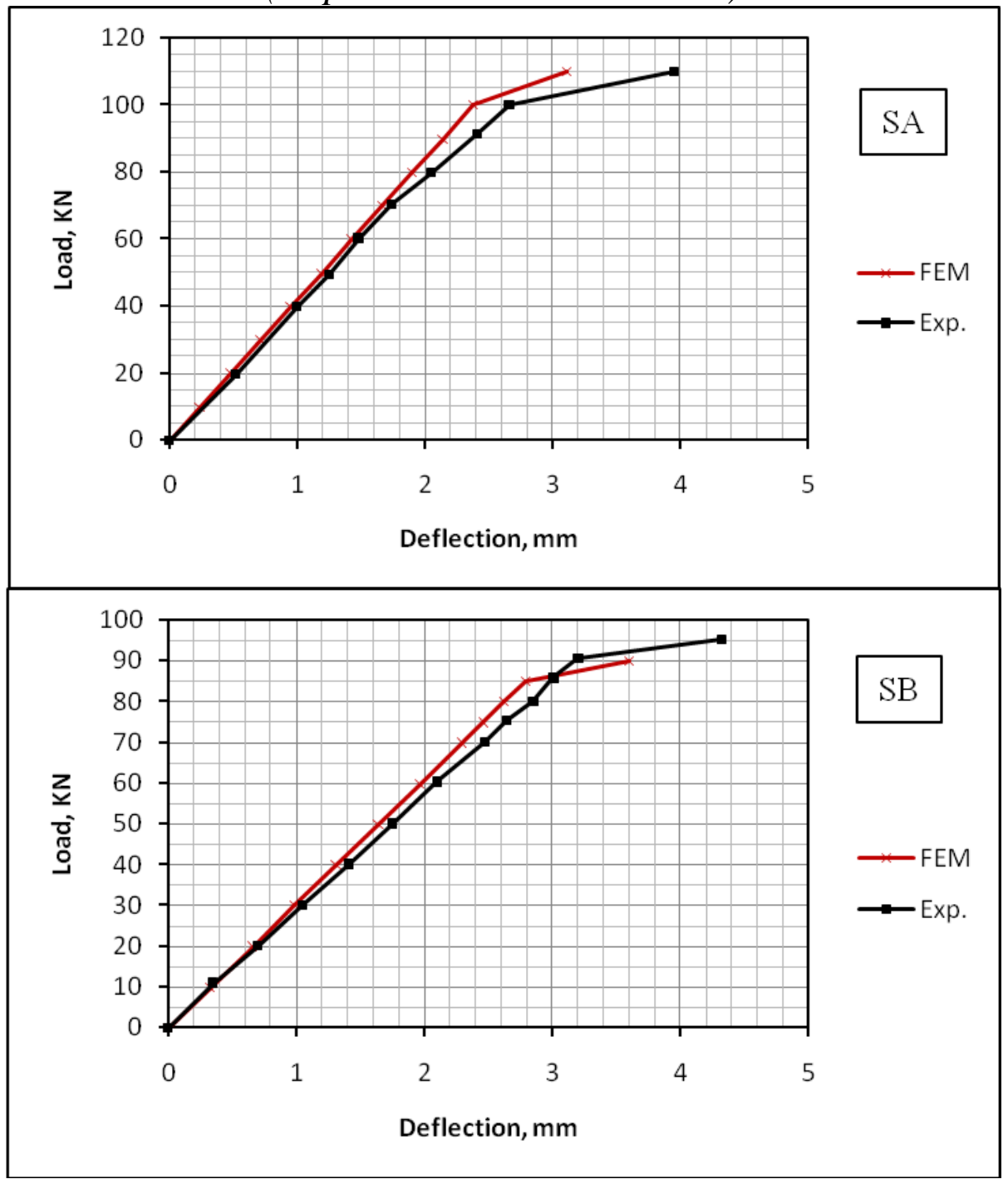

Figure (12): Load-deflection curves for slabs $S A$ and $S B$ (At point A of max. deflections) 


\subsection{Crack Pattern and Modes of Failure:}

After the initiation of shear cracks, the prestressed hollow core slabs stiffness was reduced and the load-deflection behavior ended when the failure occur. In the actual slabs, the failure is abrupt and noisy, like a small explosion. In the actual and finite element models before failure, the failure zone is completely un-cracked. When the first crack appears, the failure takes places immediately. The cracks are obtained using the Crack/Crushing plot option in "ANSYS". The ANSYS program records a crack pattern at each applied load step. Figure 13 and 14 shows evolutions of crack patterns developing for each slab at the failure-loading step. ANSYS program displays circles at locations of cracking or crushing in concrete elements. Cracking is shown with a circle outline in the plane of the crack, and crushing is shown with an octahedron outline. The first crack at an integration point is shown with a red circle outline, the second crack with a green outline, and the third crack with a blue outline [2].

The failure modes of the finite element models show good agreement with observations and data from the experimental full-scale slabs. In the actual slabs the failure mode appearing as shear failure near the support for slab SA and bond failure under the vertical load for slab SB. In the finite element models, the failure mode appears as shear failure under vertical load for slab SA and SB.

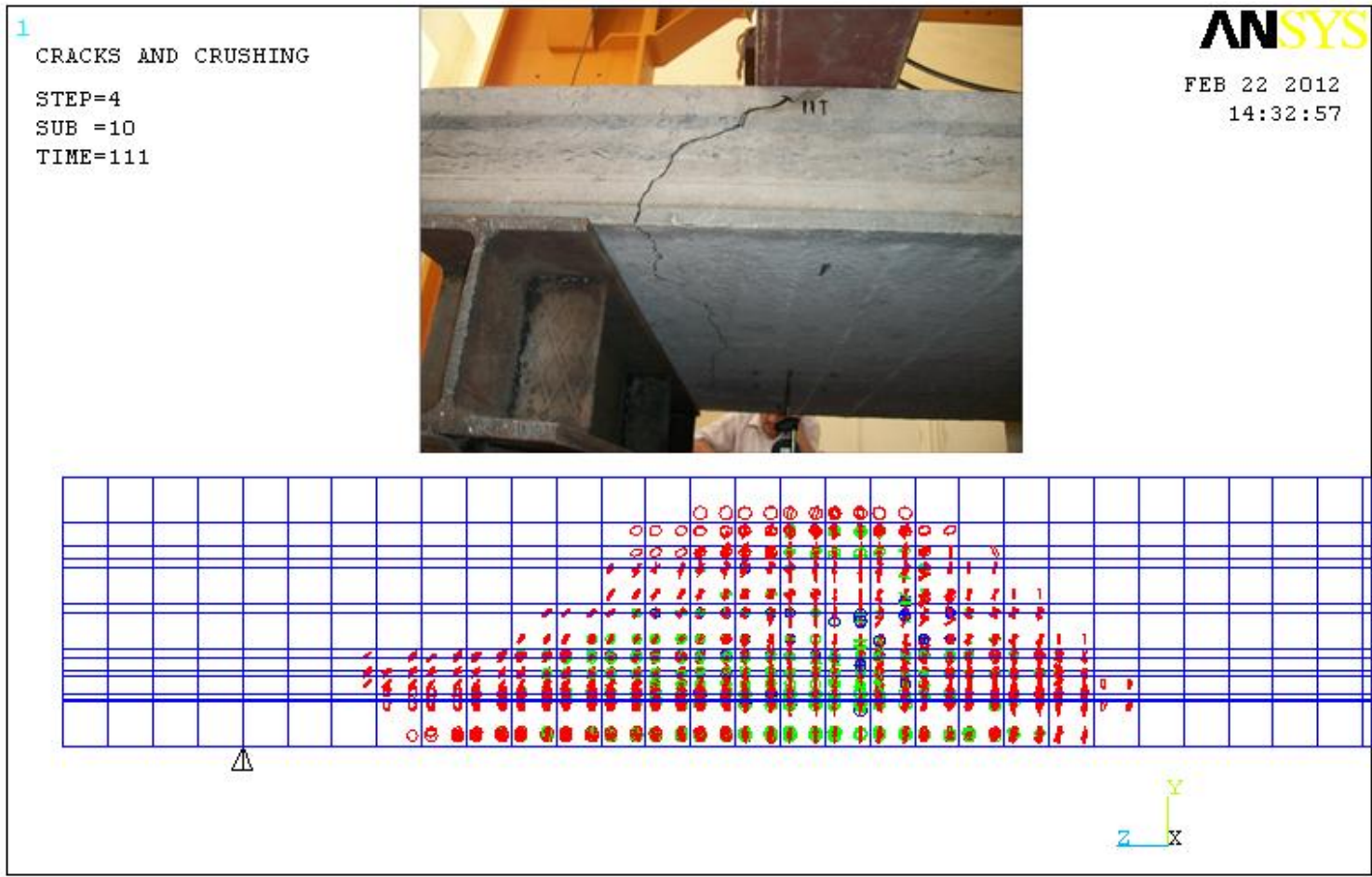

Figure (13): Crack pattern and failure modes for Exp. and FEM slab SA 


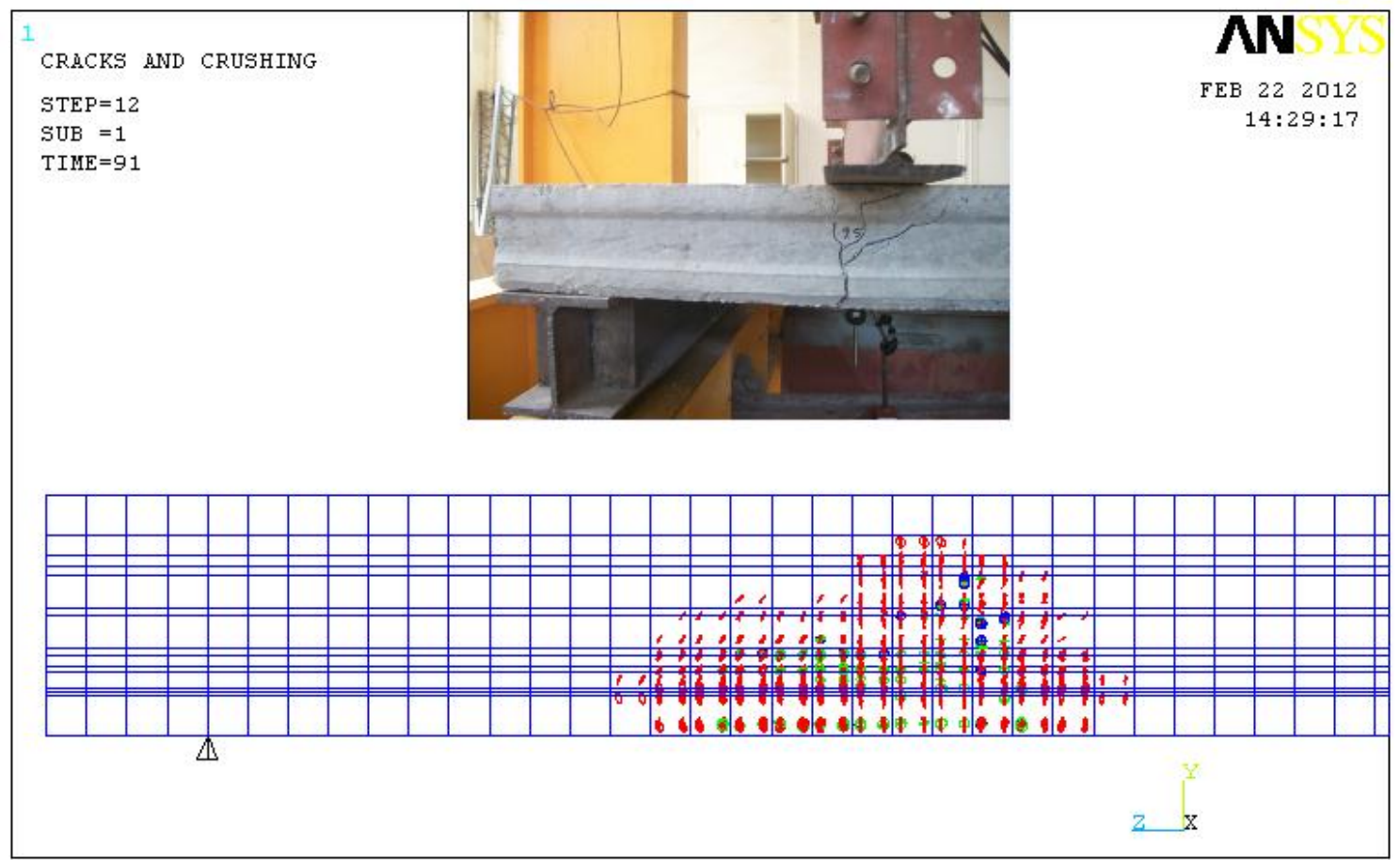

Figure (14): Crack pattern and failure modes for Exp. and FEM slab SB

\section{Conclusions:}

Based on the discussion of results obtained by numerical modeling, the following conclusions are extracted:

- The numerical solution was adopted to evaluate the ultimate shear strength of the prestressed hollow core slabs reinforced with eight prestressing strands, and compared with experimental full-scale test.

- The general behavior of the finite element models show good agreement with observations and data from the experimental full-scale slab tests.

- The present finite element model can be used in studies to develop design rules for prestressing hollow core slab members.

\section{$\underline{\text { References }}$}

[1] PCI Manual for the design of hollow core slabs, second edition (1998) By Precast/Prestressed Concrete Institute, ISBN 0-937040-57-6, U.S.A

[2] ANSYS User's Manual, Version (11.0).

[3] Anthony J. Wolanski, Flexural behavior of reinforced and pre-stressed concrete beams using finite element analysis, Thesis submitted. Milwaukee, Wisconsin. May 2004. 